\title{
Indirect estimation of flow and suspended-sediment concentration and load in small mountain streams: An exploratory study in Ribeira Seca stream, Madeira Island
}

\author{
RAQUEL LOBO ${ }^{1}$, LUIZ GUERREIRO LOPES ${ }^{2}$ * \\ ${ }^{1}$ AIDFM - Associação para Investigação e Desenvolvimento da Faculdade de Medicina, \\ Universidade de Lisboa, Av. Prof. Egas Moniz, 1649-028 Lisbon, PORTUGAL \\ ${ }^{2}$ Faculty of Exact Sciences and Engineering, University of Madeira, \\ Penteada Campus, 9020-105 Funchal, Madeira Is., PORTUGAL
}

\begin{abstract}
The aim of this study was to assess the applicability of indirect techniques for streamflow and suspended sediment concentration estimation and their use in the calculation of suspended sediment transport rate in the small mountain watersheds of Madeira Island, Portugal. Emphasis was given to the application of salt dilution gauging to the indirect determination of the flow rate and the use of water turbidity data to estimate the concentration of suspended sediments. The field and laboratory work carried out are briefly described, and the main experimental results and the field data from the short measurement campaign performed in the Ribeira Seca stream in Faial, on the north side of the island, are presented and discussed. Whilst the measurement campaign carried out was temporally and spatially limited, it was pioneering for Madeira and allowed to verify the applicability of the indirect hydrometric and sedimentometric techniques used in this exploratory study.
\end{abstract}

Key-Words: Mountain streams, streamflow, dilution gauging, suspended sediments, water turbidity, Madeira. Received: September 7, 2020. Revised: December 1, 2020. Accepted: December 14, 2020. Published: December 31, 2020.

\section{Introduction}

In mountainous regions, the occurrence of extreme hydrometeorological events such as intense rainfall and flash floods can have a significant impact on the environment and the landscape [1], with potentially severe and even catastrophic consequences for the affected communities and populations [2, 3].

The erosion processes caused by rainfall in these regions, often intensified by the inappropriate use of the soil as well as the soil disintegration and the possible occurrence of landslides caused by the action of heavy rainfall on the mountain slopes and steep hillsides, are directly responsible for the increase in the solid load in major and secondary mountain watercourses.

In addition to the direct action of rainfall erosivity, the effect of rainfall is manifested indirectly by fluvial erosion, since rainfall leads to an increase in streamflow, being the mechanical action of the water on the stream bed and the banks - which is much more accentuated in flood situations - also responsible for increasing the solid load carried by mountain rivers and streams.

As underlined by Lenzi [4], the temporal and spatial variations in the concentration of suspended sediments in mountain watercourses are typically very pronounced, with changes in concentration over time strongly dependent on flow variations.

On the other hand, the scarcity or even lack of direct flow measurements in many regions leads to the use of rainfall data for its estimation [5, 6]. However, in mountain areas, the distribution of rainfall is highly influenced by the wind direction and intensity and the very rugged topography, which has strong implications for the estimation of rainfall over the study area watersheds [7], even more so considering the usual lack of weather radars and the low spatial density of rain gauge and weather stations frequently observed in these areas [8].

In the region of Madeira, it was only in November 2017 that a C-band dual polarisation weather radar went into operation on an experimental basis at the small neighbouring island of Porto Santo, situated at a distance of more than $50 \mathrm{~km}$ northeast from Madeira Island, having been officially inaugurated only in January 2019 , long after the execution of the field measurements considered in this exploratory study.

Although radar data may capture the spatial variability of rainfall better than rain gauge data, especially in areas with unevenly and sparsely distributed rain gauge stations [9], these data may be less applicable for the quantitative rainfall estimation in mountain regions, since the correct transformation of radar reflectivity into rainfall intensity depends on several factors, such as rainfall and radar characteristics, availability of ground station measurements for adequate radar rainfall calibration to obtain accurate quantitative precipitation estimates, distance from the radar site and terrain orography [10], and it is sometimes impossible to avoid the beam blockage caused 
by terrain obstacles resulting from the complex mountain topography [11].

This is clearly the case of Madeira Island, whose complex topography, characterised by deep valleys and high mountains, with very steep slopes, induces different patterns of spatial distribution of rainfall depending on the prevailing local winds (see, e.g., [12]), with more intense winds often associated with rainfall events, which makes such estimation even more difficult and uncertain.

The distances further than $50 \mathrm{~km}$ away from the Porto Santo weather radar also contribute to increase the uncertainty of the dual-pol precipitation estimates over the island [13] and tend to underestimate the orographically enhanced rainfall [14], which can have significant implications for streamflow estimation by hydrological models.

In addition, the mountain streams on Madeira Island are of torrential nature, having a seasonal regime with higher flows during the months of October to March/April [15] and low flows during the rest of the year, especially from June to August.

Therefore, in these streams with steep slopes, it is convenient to use a flow estimation technique that can be used even under more adverse hydrometeorological conditions, which leads to considering the use of artificial tracers for such an estimation.

Different kinds of artificial tracers such as fluorescent, salt, particulate and radioactive tracers have long been used in surface and groundwater hydrology (see, e.g., [16]), with fluorescent and salt tracers being particularly useful for estimating flow rates and velocities, especially in mountain streams where other hydrometric techniques are inadequate or even cannot be used.

A natural choice when choosing the tracer to be used is sodium chloride - the common table saltdue to its low price, high availability, good solubility in water and non-harmfulness to the environment at the typical concentrations used, and the relatively affordable cost of the equipment necessary for the application of the chemical dilution method for indirect flow determination [17, 18].

On the other hand, hydrosedimentological techniques used in lowland rivers, based on the use of manual or automatic suspended-sediment samplers [19], are not the most suitable for mountain torrential streams, being even impracticable under extreme flow conditions.

However, the increase of suspended sediment load in a watercourse due to the erosion resulting from the combination of rainfall-runoff and watercourse inflows causes a corresponding increase in turbidity [20], a physical property that translates into a reduction in water transparency due to the reflection, absorption and scattering of light passing through it caused by the presence of suspended matter. This naturally leads to the consideration of the use of water turbidity measurements for estimating the suspended sediment concentration (SSC) in mountain watercourses [21], in which direct measurements may not be possible.

Thus, the main objective of this study was to assess the applicability of the indirect techniques for estimating streamflow and SSC mentioned above to the streams of Madeira Island, and their use in calculating the suspended sediment load, for which a small stream with typical characteristics for many mountain watercourses in the island was chosen.

\section{Study Area}

The watershed under study is situated on the north side of Madeira Island, a region of volcanic origin located in the Northeast Atlantic Ocean between $32^{\circ} 37^{\prime} \mathrm{N}$ and $32^{\circ} 53^{\prime} \mathrm{N}$ latitude, and $16^{\circ} 39^{\prime} \mathrm{W}$ and $17^{\circ} 17^{\prime} \mathrm{W}$ longitude, around $660 \mathrm{~km}$ from Morocco.

The island has an area of about $741 \mathrm{~km}^{2}$ and a complex topography, characterised by steep mountains (with a maximum altitude of 1,862 $\mathrm{m}$ at Pico Ruivo) and deep valleys, with $90 \%$ of its surface located above $500 \mathrm{~m}$ and a third of it above $1,000 \mathrm{~m}$ [22], consisting mainly of basaltic rocks and sedimentary formations [23].

The stream watersheds of Madeira Island have relatively small drainage areas, with main water lines with an average length of about $10 \mathrm{~km}$ and very steep longitudinal profiles, with differences in level greater than $1,400 \mathrm{~m}$ from upstream to downstream, which gives rise to turbulent regime flows and episodic torrential runoff.

The short field measurement campaign here reported was carried out in Ribeira Seca stream, a small mountain stream belonging to the Ribeira do Faial watershed, on the northern side of Madeira Island, at a location with approximate coordinates of $32^{\circ} 45^{\prime} 44.9^{\prime \prime} \mathrm{N}, 16^{\circ} 52^{\prime} 38.7^{\prime}$ ' W (see Figure 11).

The choice of the appropriate location for the measurement campaign involved a previous selection of areas and streams of potential interest, based on cartographic analysis and field knowledge of the region, followed by a careful inspection of the selected streams, aiming to identify, in each of them, the most favourable locations for carrying out measurements and collecting sediment samples, taking into account previously established technical and safety criteria.

During these inspections it was also necessary to investigate the current conditions of the stream sections potentially most suitable for carrying out this study, since almost all of the streams of the island had their natural characteristics modified as a result of the devastating flash floods, landslides and debris flows that occurred on February 20th 2010 in Madeira 


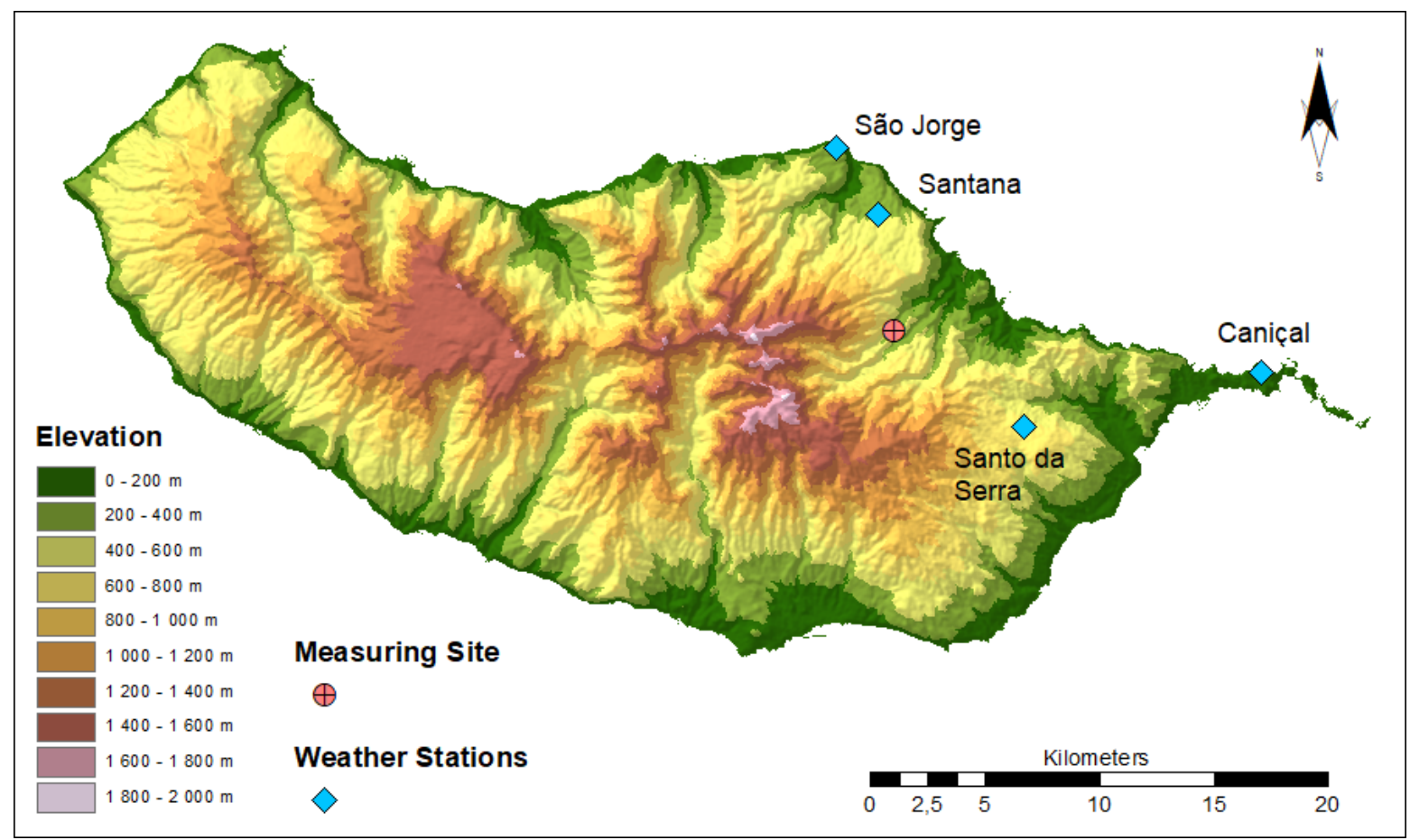

Figure 1: Location map of the study area.

Island [24, 25] - a tragedy that left 51 dead, more than 250 injured, at least 600 displaced and about 1.4 billion euros in losses - and the subsequent cleaning and removal of rocky and woody debris carried out mainly further upstream and, in some cases, the execution of regularisation and canalisation works.

Such extreme and sometimes catastrophic rainfallinduced events have been observed over centuries of Madeira's recorded history [12], and are expected to become more frequent and severe due to the expansion of the island's cities and towns, the construction of bridges and roads, and the increasing anthropization of the island's natural areas [26], even though nature-based tourism is fundamental to its economy.

The main factors considered when choosing the study site, which led to the selection of Ribeira Seca stream, were the ease of access to the stream bed and margins, the security conditions for staying near the chosen measuring point, especially under adverse hydrometeorological conditions, the nonexistence of vegetation and woody debris in the stream channel, as well as the preservation of the stream's natural characteristics and its morphology-since the measurements considered in this study were carried out just about seven and a half months after the exceptional and destructive hydro-geomorphological event mentioned above - taking also into account the need to have a stream channel with a relatively small width and the presence of narrowing zones for the correct application of the method used for flow estimation.

\section{Material and Methods}

The streamflow estimation was carried out by dilution gauging, using the mass balance method [27, 28], with sodium chloride $(\mathrm{NaCl})$ as tracer. The method, also known as dry injection method, basically consists in the instantaneous injection of a known mass of tracer into the stream and the continuous recording of the electrical conductivity (EC) of water, at a short and constant sampling interval, during the passage of the tracer cloud in a downstream measuring point, with the streamflow obtained by integrating the area under the resulting graph of tracer concentration over time.

Assuming conservation of mass-i.e. if all the tracer injected into the stream passes through the measuring section - the discharge can be estimated from the following equation [17]:

$$
M=\int Q C(t) d t
$$

where $M$ is the tracer mass injected, $Q$ is the streamflow, assumed as steady, and $C(t)$ is the tracer concentration at time $t$. Hence, from (1),

$$
Q=\frac{M}{\int C(t) d t}=\frac{M}{A}
$$

where the quantity $A$ is the area under the graph of tracer concentration over time, which can be calculated approximately as [27]:

$$
A=\sum C(t) \Delta t
$$


where $\Delta t$ is the sampling interval, i.e. the constant time interval between consecutive data points.

The instantaneous tracer concentration in the stream water is not directly measured but estimated through EC measurements, as follows [17]:

$$
C(t)=C F\left(E C(t)-E C\left(t_{0}\right)\right)
$$

where $E C(t)$ is the electrical conductivity at time $t$, $E C\left(t_{0}\right)$ is the baseline water conductivity, and the factor $C F$ is the coefficient in the (almost) linear conductivity-concentration relation obtained experimentally.

Since the time interval between measurements is constant, the stream discharge can finally be determined as follows:

$$
Q=\frac{M}{C F\left(\sum E C(t)-n E C\left(t_{0}\right)\right) \Delta t}
$$

where $Q$ is the liquid flow in $\mathrm{L} / \mathrm{s}, M$ is the mass of salt, in grams, injected into the watercourse, $\sum E C(t)$ is the sum of the conductivity values, in $\mu \mathrm{S} / \mathrm{cm}$, recorded from the injection of the salt into the watercourse until the complete passage of the salt cloud, $E C\left(t_{0}\right)$ is the baseline conductivity, also in $\mu \mathrm{S} / \mathrm{cm}, n$ is the number of readings taken during the time of passage of the tracer cloud through the sampling section, $\Delta t$ is the sampling time interval, in $\mathrm{s}$, and $C F$ is the concentration factor given by the slope of the straight line fitted to the experimental data of conductivity vs. salt concentration.

For this purpose, a WTW Cond 3310 portable conductivity meter properly calibrated and equipped with a TetraCon 325 conductivity sensor was used. This instrument has a triple scale $(0.00$ to $1,000 \mu \mathrm{S} / \mathrm{cm}, 0.000$ to $1.999 \mu \mathrm{S} / \mathrm{cm}$ and 0.00 to $19.99 \mu \mathrm{S} / \mathrm{cm}$ ) and nonlinear temperature compensation, being able to store 5,000 records with a variable sampling interval from $1 \mathrm{~s}$ to $60 \mathrm{~min}$. A ProScale XC 2000 digital pocket scale, with a capacity of $2,000 \mathrm{~g}$ and precision of $0.1 \mathrm{~g}$, was used in the field work for weighing sodium chloride, the salt used as tracer.

The physical stream characteristics and the existence of natural pools upstream and downstream of the chosen stream section has prevented a greater distance between the tracer injection point and the measurement location. However, although the ideal distance between these points is of the order of 20 to 25 times the width of the stream channel [28, 29], in many cases a distance of approximately ten times the width is sufficient to obtain reliable results with the use of the mass balance method [27]. This requirement was satisfied in this study, being the distance, in this case, of about $20 \mathrm{~m}$.

The indirect quantification of suspended sediment concentration (SSC) from water turbidity measurements was performed by the method described in
Minella et al. [21]. The measurements of water turbidity were carried out using an Analite NEP 160 handheld turbidity meter from McVan (rebranded as Observator Instruments) with a NEP 260 probe, capable of measuring the amount of solid material in suspension from the scattered light at a $90^{\circ}$ angle to the axis of the incident light in accordance with ISO 7027 standard.

The sensor probe used is capable of measuring turbidity from 0 to $3,000 \mathrm{NTU}$, a range acceptable for turbidity measurements in the streams of Madeira island - except in the case of extreme hydrological events, since turbidity measurements above 3,000 NTU correspond to sediment loads so high that they make it difficult to indirectly quantify the SSC by the adopted method - which has also been demonstrated to be suitable in other studies of suspended sediments (see, e.g., [20, 30, 31]).

In turn, the suspended sediment load (SSL) or transport rate was calculated as the product of the instantaneous suspended sediment concentration and the corresponding discharge, multiplied by a unit conversion factor [32],

$$
S S L_{i}=3.6 Q_{i} S S C_{i}
$$

where $S S L_{i}$ is the hourly suspended sediment load, expressed in metric ton $/ \mathrm{h}, Q_{i}$ is the instantaneous streamflow rate, in $\mathrm{m}^{3} / \mathrm{s}$, and $S S C_{i}$ is the instantaneous concentration of suspended sediments, in $\mathrm{g} / \mathrm{L}$.

The installation of the instruments at the measurement site was done in order to position and maintain both sensor probes inside the water, in a place relatively protected from any damage caused by rocks or woody debris in case of a rapid streamflow increase, and as close as possible to the centre of the channel flow, where the formation of air bubbles within the flow was minimal to avoid influencing the EC readings and without direct sunlight on the turbidity probe to prevent errors in measurements.

The monitoring of weather forecasts and observation of Meteosat-9 images led to the choice of the period of 5th to 7th of October 2010 for the realisation of the field work, in view of the approach of a weather front with characteristics that predicted the occurrence of rainfall with significant intensity and not too long duration, mainly concentrated on the 6th of that month.

However, the actual rainfall later registered at the weather stations of the Portuguese Institute for Sea and Atmosphere (IPMA) and the rain gauge stations maintained by the Madeira Regional Laboratory of Civil Engineering (LREC) located in the surroundings of the study area was lower than expected (see Table 1), indicating that there was a significant weakening and dissipation of the rainfall precipitation associated with that weather front. 
Table 1: Hourly rainfall recorded on 6th October at some weather stations in the vicinity of the study area.

\begin{tabular}{ccccc}
\hline Time & \multicolumn{4}{c}{ Hourly rainfall (mm) } \\
\cline { 2 - 5 }$($ GMT $)$ & Caniçal & Sto Serra & Santana & S. Jorge \\
\hline \hline $00: 00$ & 0 & 0 & 0 & 0 \\
$\vdots$ & $\vdots$ & $\vdots$ & $\vdots$ & $\vdots$ \\
$12: 00$ & 0 & 0 & 0 & 0 \\
$13: 00$ & 0 & 0 & 0 & 0.3 \\
$14: 00$ & $\vdots$ & 0 & 0 & 0 \\
$15: 00$ & 0 & 0 & 0 & 0 \\
$16: 00$ & 0 & 0.7 & 6.0 & 1.3 \\
$17: 00$ & 0.9 & 0.3 & 2.9 & 0.9 \\
$18: 00$ & 0.8 & 5.5 & 4.1 & 3.1 \\
$19: 00$ & 2.5 & 0.8 & 4.4 & 4.1 \\
$20: 00$ & 0.2 & 0.2 & 0 & 0.1 \\
$21: 00$ & 0 & 0 & 0 & 0 \\
$22: 00$ & 0 & 0 & 0.1 & 0 \\
$23: 00$ & 0 & 0 & 0 & 0 \\
\hline Total & 4.4 & 7.5 & 17.5 & 9.8 \\
\hline
\end{tabular}

The small number of measurements taken in this exploratory study was essentially due to a problem in data transfer from the EC meter to computer only detected during the field work - which could only be fixed long after the measurement campaign - and the lack of electrical support equipment that would allow the batteries of measuring instruments and laptops to be charged and provide energy to other equipment, as well as the absence of the necessary means to ensure the adequate protection of persons and the material and equipment used and allow work to continue overnight under adverse environmental conditions.

In view of that, the turbidity and conductivity measurements were, with one exception, performed alternately - which also allowed the presence of the tracer cloud resulting from the application of salt dilution gauging would not have any influence on water turbidity readings - having been carried out eight series of turbidity measurements, five of them on the 6 th of October and three on the 7th, in addition to a preliminary one made on the 5 th of the same month.

\section{Results and Discussion}

In this section are presented the experimental results obtained in laboratory from synthetic samples prepared with stream water and stream sediments at concentrations similar to those observed, together with the field measurements made in Ribeira Seca stream.

\subsection{Streamflow estimation}

The water samples collected from the stream during the field work were mixed in equal volumes aiming at homogenisation and transferred to $1 \mathrm{~L}$ volumetric flasks, where the saline solutions were prepared.
Three sets of samples with different concentrations of $\mathrm{NaCl}(0.0025 \mathrm{~g} / \mathrm{L}, 0.0065 \mathrm{~g} / \mathrm{L}, 0.0125 \mathrm{~g} / \mathrm{L}$, $0.025 \mathrm{~g} / \mathrm{L}, 0.05 \mathrm{~g} / \mathrm{L}, 0.1 \mathrm{~g} / \mathrm{L}, 0.5 \mathrm{~g} / \mathrm{L}, 1 \mathrm{~g} / \mathrm{L}, 1.5 \mathrm{~g} / \mathrm{L}$, $2 \mathrm{~g} / \mathrm{L}$ and $2.5 \mathrm{~g} / \mathrm{L}$ ) were produced and then transferred to $500 \mathrm{ml}$ beakers, where the electrical conductivity was measured and recorded automatically, with 100 readings taken for each sample.

The weighing of the required amounts of sodium chloride was done with a Mettler Toledo AG245 dual range $(210 \mathrm{~g} \times 0.1 \mathrm{mg}$ and $41 \mathrm{~g} \times 0.01 \mathrm{mg})$ analytical scale balance.

A magnetic stirrer-J.P. Selecta Agimatic-N, with adjustable speed from 60 to $1,600 \mathrm{rpm}$ - ensured the homogeneity of the salt solutions during the electrical conductivity measurements.

The values on Table Q, used in the regression analysis, are the means of the medians (which are robust against outliers) of three series of 100 EC measurements for each of the given $\mathrm{NaCl}$ concentrations.

Table 2: Mean of median values of conductivity in synthetic samples with different salt concentrations.

\begin{tabular}{cc|cc}
\hline $\begin{array}{c}\text { Salt conc. } \\
(\mathrm{g} / \mathrm{L})\end{array}$ & $\begin{array}{c}\mathrm{EC} \\
(\mu \mathrm{S} / \mathrm{cm})\end{array}$ & $\begin{array}{c}\text { Salt conc. } \\
(\mathrm{g} / \mathrm{L})\end{array}$ & $\begin{array}{c}\mathrm{EC} \\
(\mu \mathrm{S} / \mathrm{cm})\end{array}$ \\
\hline \hline 0.0000 & 202 & 0.1000 & 400 \\
0.0025 & 208 & 0.5000 & 1192 \\
0.0065 & 218 & 1.0000 & 2150 \\
0.0125 & 234 & 1.5000 & 3090 \\
0.0250 & 262 & 2.0000 & 4020 \\
0.0500 & 314 & 2.5000 & 4920 \\
\hline
\end{tabular}

The regression line obtained with these values is shown in Figure $\square$ and the corresponding regression equation is given by:

$$
C=0.0005 E C-0.1143
$$

where $C$ is the concentration of salt in water, in $\mathrm{g} / \mathrm{L}$, and $E C$ is the electrical conductivity, in $\mu \mathrm{S} / \mathrm{cm}$.

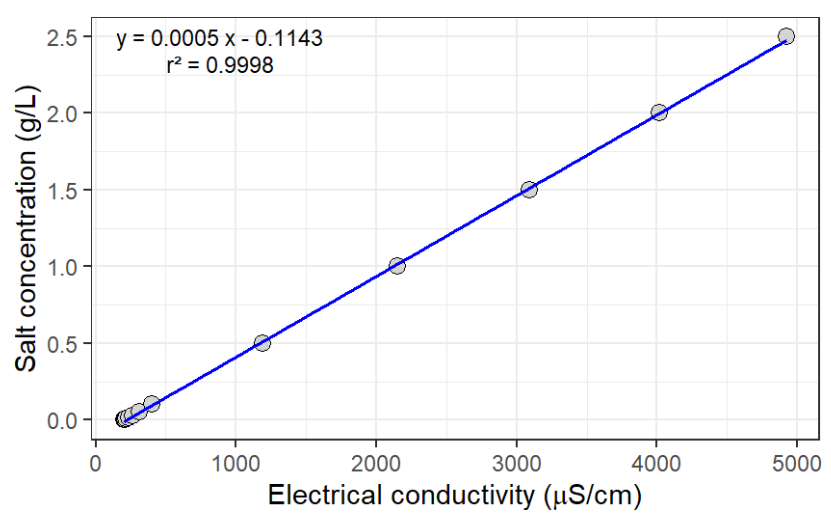

Figure 2: Relationship between measured EC and $\mathrm{NaCl}$ concentration in water obtained experimentally. 
The regression is statistically significant and the data fit the linear model almost perfectly $(r=0.9998$, $p<0.001)$.

The slope of the regression line, equal to 0.0005 , corresponds to the concentration factor $C F$ necessary for the streamflow calculation.

The first series of in situ measurements of electrical conductivity of water was carried out on the 5th October 2010, with the objective of estimating the base flow in the section of Ribeira Seca stream chosen for this study after several consecutive days without rainfall.

For this purpose, $250 \mathrm{~g}$ of salt were used, and a sampling interval $\Delta t=1 \mathrm{~s}$ was adopted for the acquisition of conductivity data. The corresponding estimate of streamflow is shown in the first row of Table 3 .

Table 3: Streamflow estimates from in situ measurements of electrical conductivity of water.

\begin{tabular}{ccccc}
\hline Date & $\begin{array}{c}\text { Time } \\
(\mathrm{GMT})\end{array}$ & $\begin{array}{c}\text { Salt } \\
(\mathrm{g})\end{array}$ & $\begin{array}{c}\Delta t \\
(\mathrm{~s})\end{array}$ & $\begin{array}{c}\text { Flow } \\
(\mathrm{L} / \mathrm{s})\end{array}$ \\
\hline \hline $2010-10-05$ & $19: 12$ & 250 & 1 & 13.3 \\
$2010-10-06$ & $19: 01$ & 500 & 1 & 50.1 \\
$2010-10-06$ & $19: 37$ & 500 & 1 & 53.1 \\
$2010-10-07$ & $12: 01$ & 250 & 1 & 51.6 \\
$2010-10-07$ & $16: 07$ & 250 & 5 & 43.1 \\
\hline
\end{tabular}

During the setup of the measurement equipment on the morning of the second day of field work, it was found that it was not possible to transfer the EC data acquired the previous day to the laptop computer, a problem that could only be fixed long after the measurement campaign. This caused the electrical conductivity records to be limited to the device's memory capacity - which enables to store up to 5,000 readings - and required careful management of the data collection time in the following measurements, taking into account the observed flow variations and the amounts of salt used. Due to this limitation, it was only possible to carry out four more series of electrical conductivity measurements, alternating in the main with measurements of water turbidity.

The resulting curves of electrical conductivity vs. time are presented in Figure 3, and the corresponding estimates of streamflow are shown from the second to the last row in Table 3, together with the quantity of salt used and the sampling interval adopted in each series of measurements. In this table, it is possible to observe that the sampling interval had to be increased to $5 \mathrm{~s}$ in the last measurement series due to the memory limitation mentioned above.

The measurement equipment was calibrated in the field prior to the EC sampling to ensure the accuracy of the measurements.

\subsection{Estimation of SSC}

The sediment samples collected in Ribeira Seca stream during the field work were first subjected to manual sieving, having been subsequently subjected to drying in a laboratory oven with forced air circulation at $60^{\circ} \mathrm{C}$ for 24 hours.

After drying, the sediments were sieved mechanically through a set of laboratory sieves, using a Retsch AS 200 Digit electromagnetic sieve shaker, in order to separate the finer fraction $(<0.075 \mathrm{~mm})$, consisting of silt and clay.

Three sets of suspensions with different concentrations $(250 \mathrm{mg} / \mathrm{L}, 500 \mathrm{mg} / \mathrm{L}, 750 \mathrm{mg} / \mathrm{L}, 1000 \mathrm{mg} / \mathrm{L}$, $1250 \mathrm{mg} / \mathrm{L}, 1500 \mathrm{mg} / \mathrm{L}, 1750 \mathrm{mg} / \mathrm{L}, 2000 \mathrm{mg} / \mathrm{L}$, $2250 \mathrm{mg} / \mathrm{L}, 2500 \mathrm{mg} / \mathrm{L}, 2750 \mathrm{mg} / \mathrm{L}, 3000 \mathrm{mg} / \mathrm{L}, 3500$ $\mathrm{mg} / \mathrm{L}, 4000 \mathrm{mg} / \mathrm{L}, 4500 \mathrm{mg} / \mathrm{L}$ and $5000 \mathrm{mg} / \mathrm{L}$ ) were prepared with the fine fraction of sediments.

The fine sediments were kept in suspension by a magnetic stirrer at the speed of $1000 \mathrm{rpm}$ at room temperature, and the suspension turbidity was measured and recorded automatically, with 100 readings taken for each sample.

The experimental values presented in Table 4, used in the regression analysis, are the means of the medians of three series of 100 readings per sample during a period of about 1 minute for each concentration.

Table 4: Mean of median values of turbidity in synthetic samples with different sediment concentrations.

\begin{tabular}{cc|cc}
\hline $\begin{array}{c}\text { SSC } \\
(\mathrm{g} / \mathrm{L})\end{array}$ & $\begin{array}{c}\text { Turbidity } \\
(\mathrm{NTU})\end{array}$ & $\begin{array}{c}\text { SSC } \\
(\mathrm{g} / \mathrm{L})\end{array}$ & $\begin{array}{c}\text { Turbidity } \\
(\mathrm{NTU})\end{array}$ \\
\hline \hline 0.25 & 45.5 & 2.25 & 650.0 \\
0.50 & 120.6 & 2.50 & 760.7 \\
0.75 & 164.1 & 2.75 & 859.0 \\
1.00 & 187.2 & 3.00 & 971.0 \\
1.25 & 268.3 & 3.50 & 1157.7 \\
1.50 & 354.3 & 4.00 & 1353.3 \\
1.75 & 431.0 & 4.50 & 1562.3 \\
2.00 & 565.3 & 5.00 & 1751.7 \\
\hline
\end{tabular}

The almost linear relationship experimentally established between water turbidity and the concentration of suspended sediments in synthetic samples prepared with fine sediments extracted from Ribeira Seca stream during the field work is shown graphically in Figure 4 .

The regression equation obtained is given as:

$$
S S C=0.0027 T U+0.4139
$$

where $S S C$ is the concentration of suspended sediments, in $\mathrm{g} / \mathrm{L}$, and $T U$ is the average turbidity in nephelometric turbidity units (NTU). This regression is statistically significant $(r=0.991, p<0.001)$ and the experimental data fit the obtained model quite closely. 
(a) October 6th, 19:01.

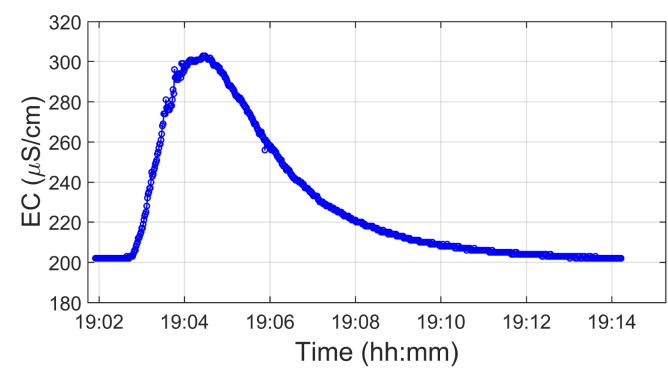

(c) October 7th, 12:01.

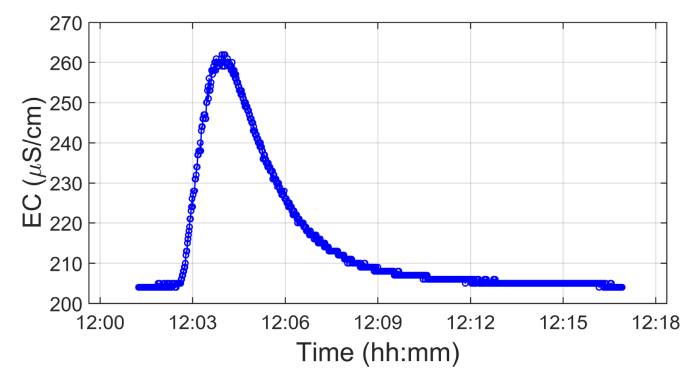

(b) October 6th, 19:37.

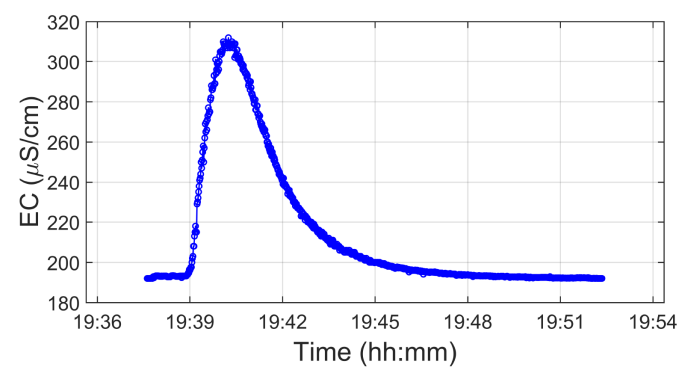

(d) October 7th, 16:07.

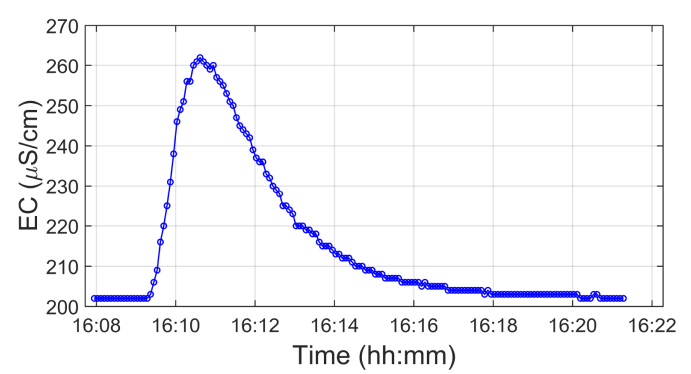

Figure 3: Electrical conductivity curves as a function of time obtained from field measurements.

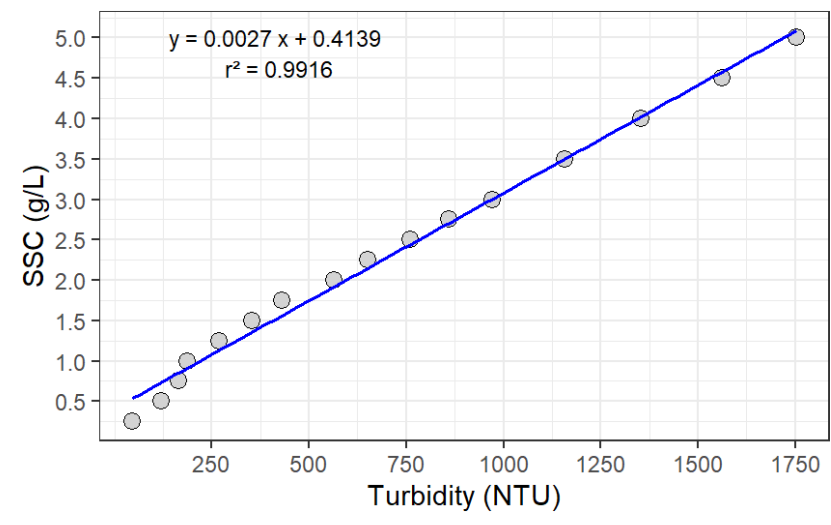

Figure 4: Relationship between measured turbidity and SSC derived from synthetic samples.

Although the sediments were kept in suspension by a magnetic stirrer, the turbidity of the sediment suspensions did not remain stable during data acquisition, the observed variations being quite marked, especially for concentrations above $3.5 \mathrm{~g} / \mathrm{L}$, as Figure 5 illustrates.

During the field work, eight series of continuous measurements of water turbidity were made in Ribeira Seca stream, five of them on the 6th of October and three on the 7th, in addition to a preliminary one made on the first day, each series corresponding to 100 records. The turbidity data for the second series of measurements made on the second day of field work are represented graphically in Figure 6.

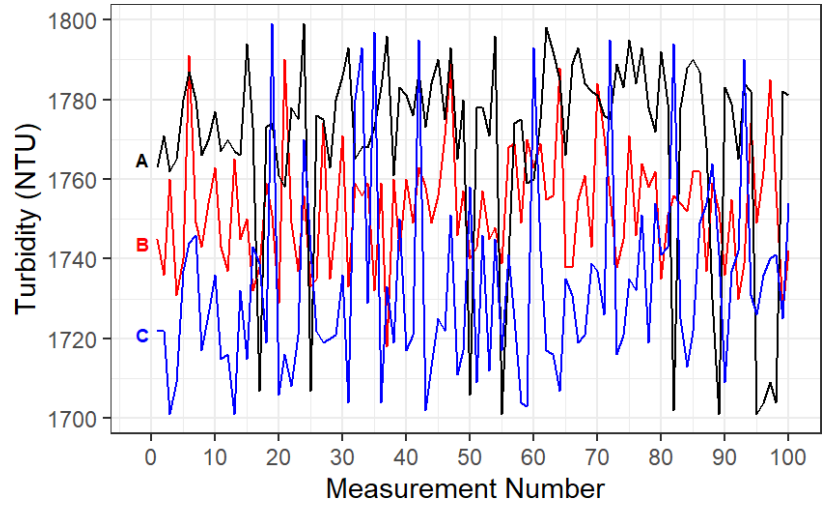

Figure 5: Turbidity measurements of three synthetic samples (A, B and C) with a concentration of $5 \mathrm{~g} / \mathrm{L}$.

The suspended sediment concentration estimates obtained from the in situ measurements carried out at the Ribeira Seca stream are presented in Table 5.

The corresponding temporal variation of the estimated suspended sediment concentration in the stream under study is graphically shown in Figure 7 .

In that figure, it is possible to observe a notable increase in the estimated concentration of suspended sediments as a result of the precipitation that occurred on the Faial watershed on the 6th of October, concentrated mainly between 16:00 and 20:00 UTM, as indicated by the precipitation values recorded at some IPMA stations located in the surroundings of the study site, given in Table 1 . 


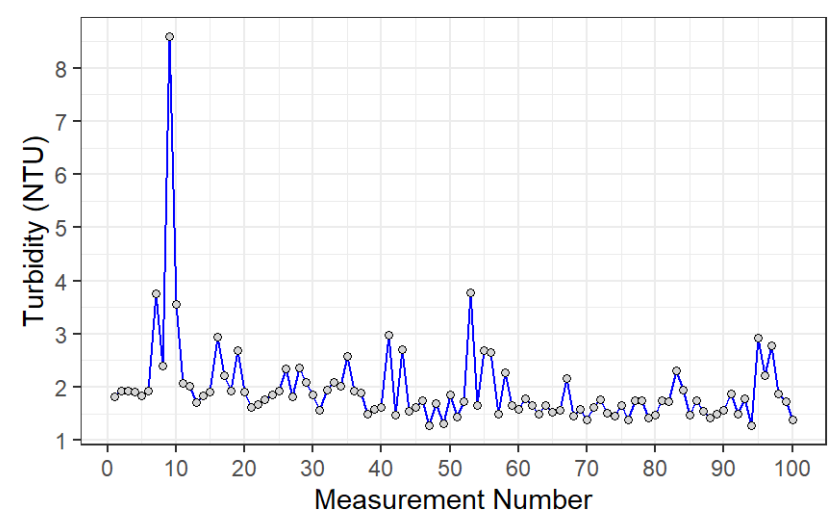

Figure 6: In situ measurements of water turbidity in Ribeira Seca stream on October 6th at 17:46.

Table 5: In situ turbidity values and respective estimates of suspended sediment concentration.

\begin{tabular}{cccc}
\hline Date & $\begin{array}{c}\text { Time } \\
(\mathrm{UTM})\end{array}$ & $\begin{array}{c}\text { Turbidity } \\
(\mathrm{NTU})\end{array}$ & $\begin{array}{c}\text { SSC } \\
(\mathrm{g} / \mathrm{L})\end{array}$ \\
\hline \hline $2010-10-06$ & $13: 25$ & 0.7 & 0.41 \\
$2010-10-06$ & $17: 46$ & 1.8 & 0.42 \\
$2010-10-06$ & $18: 29$ & 114.8 & 0.72 \\
$2010-10-06$ & $19: 12$ & 129.3 & 0.76 \\
$2010-10-06$ & $19: 40$ & 1840.0 & 5.38 \\
$2010-10-07$ & $11: 37$ & 902.5 & 2.85 \\
$2010-10-07$ & $12: 01$ & 784.0 & 2.53 \\
$2010-10-07$ & $15: 44$ & 6.4 & 0.43 \\
\hline
\end{tabular}
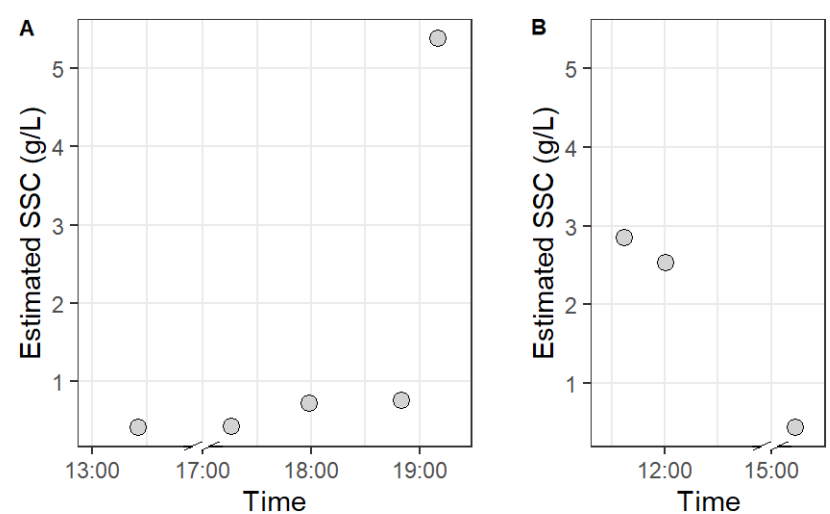

Figure 7: Temporal variation of suspended sediment concentration estimated from the measured median turbidity. A, October 6th; B, October 7th.

\subsection{Estimation of suspended sediment load}

The flow rates estimated by the chemical dilution method [27, 28] were presented on Table 3, which also indicates the mass of salt injected into the stream under study and the sampling interval adopted.

The analysis of the variation of the estimated streamflow on the basis of the rainfall data recorded on October 6th and 7th 2010 at the rain gauge and weather stations of interest shows a sharp increase of streamflow in response to the occurrence of rainfall in the aforementioned period between 16:00 and 20:00 UTM on October 6th, as well as a gradual decrease in streamflow after the end of rainfall the following morning. These variations in discharge were accompanied by corresponding changes in suspended sediment load, as is possible to observe in Table 6, which summarises all the estimates obtained from the measurements performed during the field work.

Table 6: Estimates of streamflow and suspendedsediment concentration and load.

\begin{tabular}{ccccc}
\hline Date & $\begin{array}{c}\text { Time } \\
(\mathrm{UTM})\end{array}$ & $\begin{array}{c}\text { Flow } \\
(\mathrm{L} / \mathrm{s})\end{array}$ & $\begin{array}{c}\text { SSC } \\
(\mathrm{g} / \mathrm{L})\end{array}$ & $\begin{array}{c}\text { SSL } \\
(\mathrm{kg} / \mathrm{h})\end{array}$ \\
\hline \hline $2010-10-05$ & $19: 12$ & 13.3 & - & - \\
$2010-10-06$ & $13: 25$ & - & 0.41 & - \\
$2010-10-06$ & $17: 46$ & $13.3^{a}$ & 0.42 & 20.1 \\
$2010-10-06$ & $18: 29$ & - & 0.72 & - \\
$2010-10-06$ & $19: 01$ & 50.1 & - & - \\
$2010-10-06$ & $19: 12$ & $51.0^{b}$ & 0.76 & 139.5 \\
$2010-10-06$ & $19: 37$ & 53.1 & - & - \\
$2010-10-06$ & $19: 40$ & - & 5.38 & - \\
$2010-10-07$ & $11: 37$ & - & 2.85 & - \\
$2010-10-07$ & $12: 01$ & 51.6 & 2.53 & 470.0 \\
$2010-10-07$ & $15: 44$ & $43.9^{b}$ & 0.43 & 68.0 \\
$2010-10-07$ & $16: 07$ & 43.1 & - & - \\
\hline${ }^{a}$ Assumed unchanged before start of rainfall; ${ }^{b}$ Interpolated value.
\end{tabular}

As it is also possible to observe in the table above, in the mid-afternoon of the third day of field work the estimated concentration of suspended sediments had already practically returned to its initial value around $0.4 \mathrm{~g} / \mathrm{L}$, calculated from the turbidity measurements made before the occurrence of precipitation, although the flow rate was still relatively high.

Due to the fact that most of the conductivity and turbidity measurements were not simultaneous, some streamflow estimates for the time of the turbidity measurements that appear in Table 6 were obtained through linear interpolation between the temporally closest flow estimates, as indicated in the note below the table. It should also be noted that it was assumed that the flow rate initially estimated at $13.3 \mathrm{~L} / \mathrm{s}$ did not decrease significantly, remaining practically the same until the beginning of rainfall on October 6th, as was also mentioned in the note on Table 6 .

The suspended sediment load estimates shown in the last column of the same table were obtained using Equation (8) with the estimated streamflow values and the corresponding SSC estimates. These estimates allow to obtain a reasonable idea of the order of magnitude of the suspended sediment transport in Ribeira Seca stream during the period considered. 


\section{Conclusion}

Although the temporal and spatial limitations of the measurement campaign performed in the Ribeira Seca stream did not allow to obtain a more representative conclusion on the suspended sediment transport in the watershed under study, the work carried out allowed assess and master the field and laboratory methods and techniques used in this type of study, as well as to verify the applicability of such techniques to the chosen watercourse, and by extension to other similar mountain torrential streams on Madeira Island, where other traditional hydrometric and sedimentometric techniques, and also more recent techniques like acoustic Doppler profiling (ADP) may not be the most suitable or are even impracticable under severe hydrological conditions.

This study was pioneering for Madeira Island and may serve as a basis for future studies on the island's watersheds using the same techniques. This kind of study is important due the fact that Madeira is a region that has nature-based tourism as one of the pillars of its economy and were an adequate knowledge of the hydrologic and hydraulic behaviour of the mountain catchments under intense rainfall is an essential requirement for preserving the landscape, protecting the integrity of buildings and infrastructure and ensuring the safety of the island's residents and visitors.

In this study, a strong positive linear correlation was observed between turbidity and suspended sediment concentration. However, the results obtained in laboratory indicate that the continuous measurements of water turbidity carried out when the suspended sediment concentrations are high, typically above $3,500 \mathrm{mg} / \mathrm{L}$, show more accentuated variations due to the less homogeneous distribution of suspended sediments in the water.

Regarding the streamflow estimation based on the dilution gauging method, it was found that this estimation is strongly dependent on the characteristics of the waterline, namely the roughness and sinuosity of the stream channel, the presence of plants and woody debris along the chosen stream section, and the water turbulence at the measurement site.

The suspended sediment discharge, obtained from the indirect estimation of flow rate and suspended sediment concentration, showed a variation of the order of 0.45 metric ton $/ h$, explained by changes both in the flow rate and in the erosive power and sediment transport capacity of the stream resulting from the variations in the rainfall intensity observed during the monitored event.

The results obtained seems to indicate that the sediment transport in suspension, namely in mountain watersheds where direct measurements of suspended sediments can be of high risk or even not possible during extreme hydrological events, can be evaluated with reasonable accuracy using estimates of suspended sediment concentration derived from turbidity measurements. However, taking into account the high price of the commercial continuous recording turbidity meters and their relatively low autonomy and limited data storage capacity, in addition to the risk of damage or loss of equipment in mountain watersheds under adverse hydrological conditions, it is convenient to use for that purpose low cost turbidity meters capable of operating and recording turbidity data for long periods of time (see, e.g. [33]), which can be installed simultaneously in and along several waterlines, thus allowing to obtain a more comprehensive characterisation and analysis of the sediment dynamics at the watershed scale.

\section{Acknowledgements}

A preliminary and shorter version of this paper in Portuguese was presented at an internal meeting of the Mountain Research Center (CIMO), IPB, Portugal. The authors wish to thank Prof. Nereida Cordeiro, Dept. of Chemistry, University of Madeira, for making your lab equipment available for the experimental work involving the preparation and analysis of the samples required for this study. They would also like to thank IPMA, I.P. and LREC, and Dr. Victor Prior and Dr. Carlos Magro for the rainfall and meteorological data provided for this study. The authors also acknowledge Elias Lobo and his company for the logistical support to the field campaign, Celeste Ladeira and Pedro Rodrigues for their help in the field work, and Narcisa Teixeira for helping with the lab work.

\section{References:}

[1] Beniston, M., Environmental Change in Mountains and Uplands, Arnold, London, 2000.

[2] García-Ruiz, J. M., Martí-Bono, C., Lorente, A., and Beguería, S., Geomorphological consequences of frequent and infrequent rainfall and hydrological events in Pyrennez mountains of Spain, Mitigation and Adaptation Strategies for Global Change, Vol. 7, No. 3, 2002, pp. 303-320. doi:10.1023/A:1024479630433

[3] Bacchi, B. and Villi, V., Runoff and floods in the Alps: an overview, in De Jong, C., Collins, D. and Ranzi, R. (eds.), Climate and Hydrology in Mountain Areas, Wiley, Chichester, UK, 2005, pp. 217-220.

[4] Lenzi, M. A., Variation in suspended sediment concentration during floods in the instrumented catchment of the Rio Cordon, in Lenzi, M. A. (ed.), Dynamics of Water and Sediments in Mountain Basins, Bios, Cosenza, 2000, pp. 53-67. 
[5] Yanto, Livneh, B., Rajagopalan, B., Kasprzyk, J., Hydrological model application under data scarcity for multiple watersheds, Java Island, Indonesia, Journal of Hydrology: Regional Studies, Vol. 9, 2017, pp. 127-139. doi:10.1016/j.ejrh.2016.09.007

[6] Alipour, M., Streamflow Prediction in Ungauged Basins Located Within Data-Scarce Regions, $\mathrm{PhD}$ Thesis, University of Central Florida, Orlando, FL, 2019.

[7] Johansson, B. and Chen, D., Estimation of areal precipitation for runoff modelling using wind data: a case study in Sweden, Climate Research, Vol. 29, No. 1, 2005, pp. 53-61. doi: $10.3354 / \mathrm{cr} 029053$

[8] Weingartner, R., Barben, M., and Spreafico, M., Floods in mountain areas - an overview based on examples from Switzerland, Journal of Hydrology, Vol. 282, No. 1-4, 2003, pp. 10-24. doi:10.1016/S0022-1694(03)00249-X

[9] Canli, E., Loigge, B., and Glade, T., Spatially distributed rainfall information and its potential for regional landslide early warning systems, Natural Hazards, Vol. 91, Suppl. 1, 2018, pp. 103-127. doi:10.1007/s11069-017-2953-9

[10] Wohl, E., Mountain Rivers Revisited, American Geophysical Union, Washington, DC, 2010.

[11] McRoberts, D. B. and Nielsen-Gammon, J. W., Detecting beam blockage in radar-based precipitation estimates, Journal of Atmospheric and Oceanic Technology, Vol. 34, No. 7, 2017, pp. 1407-1422. doi:10.1175/JTECH-D-16-0174.1

[12] Gouveia-Reis, D., Lopes, L. G., Mendonça, S., A dependence modelling study of extreme rainfall in Madeira Island, Physics and Chemistry of the Earth, Vol. 94, 2016, pp. 85-93. doi:10.1016/j.pce.2015.11.006

[13] Gesell, I. W., A Statistical Comparison of the Accuracy of Precipitation Estimation Using Dual-Polarization and Single-Polarization Radar, Senior Thesis, Iowa State University, Ames, IA, 2017.

[14] Zhang, J., Qi, Y., Kingsmill, D. E., and Howard, K., Radar-based quantitative precipitation estimation for the cool season in complex terrain: Case studies from the NOAA Hydrometeorology Testbed, Journal of Hydrometeorology, Vol. 13, No. 6, 2012, pp. 1836-1854. doi:10.1175/JHMD-11-0145.1
[15] Shahin, M., Hydrology and water resources of African islands, in Hydrology and Water Resources of Africa, Kluwer, Dordrecht, 2002, pp. 565-582.

[16] Leibundgut, C., Maloszewski, P., and Külls, C., Artificial tracers, in Tracers in Hydrology, WileyBlackwell, Chichester, UK, 2009, pp. 57-122.

[17] Bolognesi, A., Gottardi, G., and Maglionico, M., Discharge measurements in a small ungauged river: comparison between conventional currentmeter and tracer dilution methods, in Ferreira, R. M. L., Alves, E. C. T. L., Leal, J. G. A. B. and Cardoso, A. H. (eds.), River Flow 2006: Proceedings of the International Conference on Fluvial Hydraulics, Taylor \& Francis, London, 2006, pp. 1835-1842.

[18] Moore, R. D., Introduction to salt dilution gauging for streamflow measurement: Part 1, Streamline Watershed Management Bulletin, Vol. 7, No. 4, 2004, pp. 20-23.

[19] Boiten, W., Hydrometry, 3rd ed., CRC Press/ Balkema, Leiden, 2008.

[20] Neupane, S., Vogel, J. R., Storm, D. E., Barfield, B. J., and Mittelstet, A. R., Development of a turbidity prediction methodology for runofferosion models, Water, Air, \& Soil Pollution, Vol. 226, 2015, Article 415. doi:10.1007/s11270015-2679-9

[21] Minella, J. P. G., Merten, G. H., Reichert, J. M., and Clarke, R. T., Estimating suspended sediment concentrations from turbidity measurements and the calibration problem, Hydrological Processes, Vol. 22, No. 12, 2008, pp. 1819-1830. doi:10.1002/hyp.6763

[22] Sziemer, P., Madeira's Natural History in a Nutshell, Francisco Ribeiro \& Filhos, Funchal, 2000.

[23] Carvalho, A. M. G. and Brandão, J. M., Geologia do Arquipélago da Madeira, Museu Nacional de História Natural, Lisbon, 1991.

[24] Nguyen, H. T., Wiatr, T., Fernández-Steeger, T. M., Reicherter, K., Rodrigues, D. M. M., and Azzam, R., Landslide hazard and cascading effects following the extreme rainfall event on Madeira Island (February 2010), Natural Hazards, Vol. 65, No. 1, 2013, pp. 635-652. doi:10.1007/s11069-012-0387-y

[25] Fragoso, M., Trigo, R. M., Pinto, J. G., Lopes, S., Lopes, A., Ulbrich, S., and Magro, C., The 20 February 2010 Madeira flash-floods: synoptic 
analysis and extreme rainfall assessment, Natural Hazards and Earth System Sciences, Vol. 12, No. 3, 2012, pp. 715-730. doi:10.5194/nhess-12715-2012

[26] Baioni, D., Human activity and damaging landslides and floods on Madeira Island, Natural Hazards and Earth System Sciences, Vol. 11, No. 11, 2011, pp. 3035-3046. doi:10.5194/nhess$11-3035-2011$

[27] Hudson, R. and Fraser, J., Introduction to salt dilution gauging for streamflow measurement, Part IV: the mass balance (or dry injection) method, Streamline Watershed Management Bulletin, Vol. 9, No. 1, 2005, pp. 6-12.

[28] Elder, K., Kattelmann, R., and Fergusson, R., Refinements in dilution gauging for mountain streams, in Lang, H. and Musy, A. (eds.), Hydrology in Mountainous Regions, I: Hydrological Measurements; the Water Cycle, IAHS Press, Wallingford, UK, 1990, pp. 247-254.

[29] Day, T. J., Observed mixing lengths in mountain streams, Journal of Hydrology, Vol. 35, No. 1-2, 1977, pp. 125-136. doi:10.1016/00221694(77)90081-6

[30] Mao, L. and Carrillo, R., Temporal dynamics of suspended sediment transport in a glacierized Andean basin, Geomorphology, Vol. 287, 2017, pp. 116-125. doi:10.1016/j.geomorph.2016.02.003

[31] Tuset, J., Vericat, D., and Batalla, R. J., Water and sediment budgets unveiling contrasting hydro-sedimentary patterns in a mountainous Mediterranean catchment, Science of the Total Environment, Vol. 745, 2020, Article 140884. doi:10.1016/j.scitotenv.2020.140884
[32] Mano, V., Nemery, J., Belleudy, P., and Poirel, A., Assessment of suspended sediment transport in four alpine watersheds (France): influence of the climatic regime, Hydrological Processes, Vol. 23, No. 5, 2009, pp. 777-792. doi:10.1002/hyp.7178

[33] Gonçalves, C.C., Gomes, L.A., and Lopes, L.G., Low-cost continuous turbidity meter/recorder for suspended sediment monitoring in mountain streams, in Andrade, C. (ed.), Book of Abstracts, International Conference on Ecohydrology and Climate Change - EcoHCC'09, Polytechnic Institute of Tomar, Tomar, Portugal, 2009, p. 73.

\section{Authors' Contributions}

Both authors were responsible for the conceptualisation and design of the study. The first author (R.L.) carried out the field and laboratory work, performed the data analysis and wrote an earlier and shorter version of this paper as part of her thesis work, developed under the supervision of the second author (L.G.L.). The second author helped in the field work, and critically reviewed, updated, expanded and improved the original draft of the manuscript.

\section{Creative Commons Attribution License 4.0 (Attribution 4.0 International, CC BY 4.0)}

This article is published under the terms of the Creative Commons Attribution License 4.0.

https://creativecommons.org/licenses/by/4.0/deed.en US 